\title{
Analysis of the Surface Temperature and Energy Performance for the Double Paned Glazing Filled with Carbon Dioxide as an Insulating Gas
}

\author{
Sanghoon Baek ${ }^{1}$, Sangchul Kim* ${ }^{2}$
}

1 Research Professor, Industry Academic Cooperation Foundation, Hankyong National University, 327, Jungang-ro, Anseong-si, Gyeonggi-do 17579, Korea

$* 2$ Anseong-si, Gyeonggi-do 17579, Korea

shbaek2018@gmail.com ${ }^{1}$, sckim08@hknu.ac.kr²

Corresponding author ${ }^{*}$ : mobile Phone: $+82-010-3653-9502$

Article History:Received:11 november 2020; Accepted: 27 December 2020; Published online: 05 April 2021

Abstract : Background/Objectives: The purpose of this study is to develop a double glass infused with $\mathrm{CO} 2$ as a part of the work to resource greenhouse gases in buildings.

Methods/Statistical analysis: In the case of analysis of the results, the analysis point was focused on January during the heating period with a large indoor/outdoor temperature difference. The amount of energy lost, and the amount of heating energy used in the room. In addition, details of the concept, characteristics, and heat transfer process of the $\mathrm{CO} 2$ double glass have been described in detail in the previous study and will be omitted in this paper.

Findings: This study aims to analyze the insulating and energy performances for the double paned glazing filled with carbon dioxide $(\mathrm{CO} 2)$ gas as one of works to utilize greenhouse gases in buildings . For this, double paned glazing with $\mathrm{CO} 2$, Air, Argon, and Krypton gases respectively apply to the building designed by the computer simulation program, and then, hourly surface temperatures in the indoor pane, hourly energy losses, and total energy consumption in the building are compared. The simulation programs are Therm \& Window and EnergyPlus. The results revealed that the indoor surface temperatures of the glazing with $\mathrm{CO} 2$ gas are located between the glazing with Air and Krypton gases, and are similar to the glazing with Argon gas. In analysis of energy performance, it was shown that the building with CO2 glazing consumes heating energy at a similar level to the case of Argon gas.

Improvements/Applications: The insulation and energy performance when $\mathrm{CO} 2$ gas was injected into the double glass was verified, and it was found that it exhibited similar performance to the existing Ar gas and thus has high potential as an insulating gas.

Keywords: Carbon dioxide, Double paned glazing, Energy performance, Greenhouse gas, EnergyPlus.

\section{Introduction}

The main greenhouse gases that cause global warming are carbon dioxide $(\mathrm{CO} 2)$, methane $(\mathrm{CH} 4)$, nitrous oxide (N2O), fluorinated carbon (HRCs), perfluorocarbons (PFCs), and sulfur hexafluoride (SF6). Of these, CO2 is the most greenhouse gas emitted in the atmosphere by artificial production activities in each industry. Therefore, in order to effectively mitigate global warming, it is essential to develop technologies that capture and store $\mathrm{CO} 2$ already emitted while reducing $\mathrm{CO} 2$ emissions from production activities. In particular, in Korea, it has long focused on the development of technologies for capturing and storing $\mathrm{CO} 2$ in the atmosphere, and as a result, technologies that can capture and store $\mathrm{CO} 2$ and control it artificially have developed to a considerable level. Most of these captured and stored $\mathrm{CO} 2$ is permanently buried in the ground, but some $\mathrm{CO} 2$ gases are regenerated through chemical separation technology and mechanical process technology, and are reused as resources in each industry.[1]

While various efforts have been made to utilize stored $\mathrm{CO} 2$ as a resource in other industries, the building sector is focusing on reducing $\mathrm{CO} 2$ emissions, and research and technologies to utilize $\mathrm{CO} 2$ as a resource are still somewhat insufficient. to be. In particular, from the viewpoint of heat and energy, pure CO2 gas can exhibit higher thermal insulation performance than air and is relatively inexpensive. Therefore, if CO2 is used as a heat insulating material in a building, it will be able to exhibit effective heat insulation performance at a low cost. [24]

The only element that can use gaseous $\mathrm{CO} 2$ as an insulating material in a building will be the hollow layer of the double glazing of the building envelope and windows. Of these, since it is almost impossible to form the hollow layer of the building envelope into a completely enclosed space, there is a very high risk of being discharged back into the atmosphere even when $\mathrm{CO} 2$ gas is injected. In contrast, since the hollow layer of the double glass in the window can be kept in a completely sealed state by applying two or more sheets of glass and edge sealing technology, there is little risk of being discharged into the atmosphere even when $\mathrm{CO} 2$ is injected. [5] If $\mathrm{CO} 2$ is used as an insulating gas in double glass, the price of windows can be considerably lowered by replacing the existing expensive insulating gases Argon (Ar) and Krypton (Kr) with CO2. In particular, existing

*Corresponding author: Sangchul Kim

Professor, School of Architecture \& Design Convergence, Hankyong National University, 327, Jungang-ro,

Anseong-si, Gyeonggi-do 17579, Korea.sckim08@hknu.ac.kr 
windows and doors have been recognized as a building element that releases $\mathrm{CO} 2$ gas by promoting the consumption of cooling and heating energy in buildings, but if one of the greenhouse gases, $\mathrm{CO} 2$, is injected into the glass, the building with such glass is $\mathrm{CO} 2$ like forest. It can have the advantage that can be converted into architectural elements that absorb. Therefore, this study aims to develop a double glass infused with CO2 as part of the work to make greenhouse gases into resources in buildings. To do this, a wide range of research and verification must be conducted, including verification of thermal insulation performance for $\mathrm{CO} 2$ gas, determination of the optimal thickness of gas, fusion of frame and edge sealing technology, and possibility of fusion with other technologies for super insulation such as vacuum and suspended film. The current study focuses on verifying the adiabatic performance of $\mathrm{CO} 2$ gas as an initial step. In this regard, this author compared the insulation performance of $\mathrm{CO} 2$ gas with Air, $\mathrm{Ar}$, and $\mathrm{Kr}$ gases, which have been widely used as insulating gases for glass, by using the Thermal \& Window program, a glass and window analysis program in the previous study. As a result, the adiabatic performance of $\mathrm{CO} 2$ gas was higher than Air and lower than $\mathrm{Kr}$ gas. In particular, it was analyzed that the double glass injected with $\mathrm{CO} 2$ in terms of the heat transfer rate Uvalue showed a very similar U-value value to the double glass injected with Ar gas. When applied, as in the existing U-value analysis results, the computer simulation program is to verify whether the double glass with $\mathrm{CO} 2$ in the actual building exhibits similar energy performance to the double glass with Ar gas.

As a research method, first, a modeling method of windows and buildings for performing computer simulation, as well as indoor and outdoor environmental conditions and heating and cooling equipment conditions applied to the simulation will be described. In addition, in the case of analysis of results, the time of analysis focused on January during the heating period with a large indoor/outdoor temperature difference. The amount of energy lost, and the amount of heating energy used in the room. In addition, the details of the concept, characteristics, and heat transfer process of $\mathrm{CO} 2$ double glass are omitted in this paper because they have been described in detail in the previous study. [6] Window and Energy Analysis program, EnergyPlus version 8.7. In addition, for the overall theory and analysis methodology for calculating the surface temperature, heat transfer process inside the glass, and deriving energy consumption during the simulation process, refer to the EnergyPlus Engineering Reference. [7,14,15]

\section{Research Methods}

\subsection{Composition of carbon dioxide double glass}

Fig. 1 shows the structure and characteristics of the $\mathrm{CO} 2$ double glass proposed in this study. The system consists of two sheets of glass, $\mathrm{CO} 2$ gas, edge sealing, and a frame, just like a normal double glass. In particular, Edge sealing that seals the gas layer is composed of Primary sealing (Spacer bar) and Secondary sealing including desiccant. Also, in order to apply such glass in EnergyPlus, thermal and physical values for glass, $\mathrm{CO} 2$ gas, and frame must be entered. First, in the case of glass, the Therm \& Window program provided by Lawrence Berkeley National Laboratory (LBNL) includes various types of glass produced in each country, and is constantly updated every year.[8] Therefore, the glass applied to this simulation is It is a low-emission glass produced by 'Saint-Gobain Glass', one of the glasses provided by LBNL, and the thickness of the glass was selected as $5 \mathrm{~mm}$, which is generally widely used. Table 1 shows the thermal conductivity of the glass and the optical properties of the front and back surfaces.

(Double Pane Glazing)

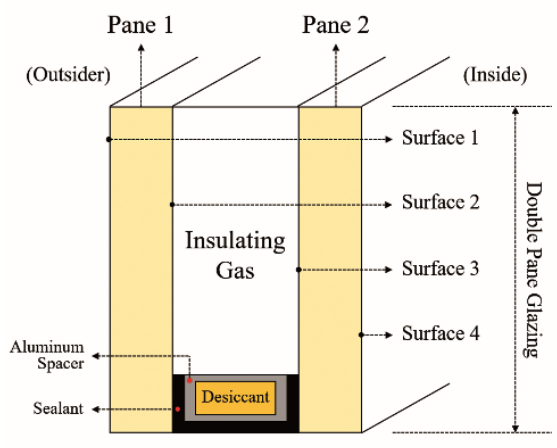

(Double Pane Window)

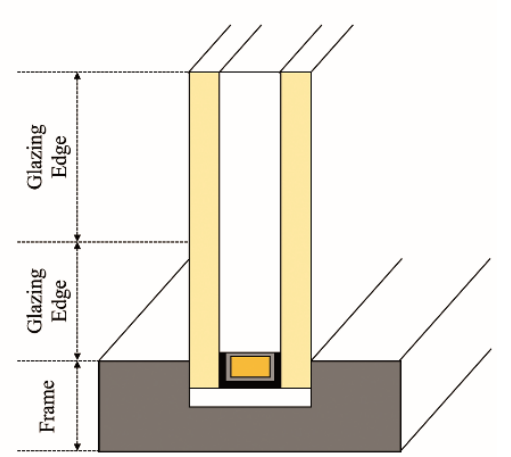

Fig. 1 The structure of the double paned glazing with $\mathrm{CO} 2$ gas

In addition, Table 2 shows the thermal and physical values of each gas at standard atmospheric pressure as an insulating gas applied to EnergyPlus.[9] The thickness of the gas is $10 \mathrm{~mm}$, which is generally applied in actual double glass. In particular, in order to verify the level of insulation and energy performance of double glass by $\mathrm{CO} 2$ gas, the insulating gases of the existing double glass, Air, $\mathrm{Ar}$, and $\mathrm{Kr}$ gases were applied as comparison objects. In addition, Table 3 shows the material and thickness of the frame combined with the double glass, the thermal conductivity, and the length protruding from the double glass. The total thickness of the double glass 
Analysis of the Surface Temperature and Energy Performance for the Double Paned Glazing Filled with Carbon Dioxide as an Insulating Gas

combined with these materials is $20 \mathrm{~mm}$, and the total width of the windows applied to the building by combining the double glass and the frame is $220 \mathrm{~mm}$.

Table 2 The thermal characteristics of Air, A, Kr, and $\mathrm{CO} 2$ gases

\begin{tabular}{cccccc}
\hline \multicolumn{2}{c}{ Type of insulating gas } & Air & Ar & $\mathrm{Kr}$ & $\mathrm{CO} 2$ \\
\hline Thickness & $(\mathrm{mm})$ & 10 & 10 & 10 & 10 \\
\hline Molecular Weight & $(\mathrm{mol} / \mathrm{g})$ & 28.970 & 39.948 & 83.800 & 44.010 \\
\hline Pressure & $(\mathrm{Pa})$ & 101325 & 101325 & 101325 & 101325 \\
\hline Prandtl Number & & 0.7197 & 0.6704 & 0.6717 & 0.7808 \\
\hline Conductivity coefficients & $(\mathrm{W} / \mathrm{m} \cdot \mathrm{K})$ & 0.002873 & 0.002285 & 0.0009443 & 0.00037 \\
\hline Viscosity coefficients & $(\mathrm{kg} / \mathrm{m} \cdot \mathrm{s})$ & 0.00000372 & 0.00000338 & 0.00000221 & 0.00000116 \\
\hline Specific heat coefficients & $(\mathrm{J} / \mathrm{kg} \cdot \mathrm{K})$ & 1002.7 & 521.9 & 248.1 & 558.8 \\
\hline
\end{tabular}

Table 3 The type and thermal characteristics of the frame system

\begin{tabular}{ccccc}
\hline Type of frame & Material & $\begin{array}{c}\text { Thickness } \\
(\mathrm{m})\end{array}$ & $\begin{array}{c}\text { Projected length } \\
(\mathrm{m})\end{array}$ & $\begin{array}{c}\text { Conductivity } \\
(\mathrm{W} / \mathrm{m} \cdot \mathrm{K})\end{array}$ \\
\hline Side sliding & PVC & 0.08 & 0.1 & 0.16 \\
\hline
\end{tabular}
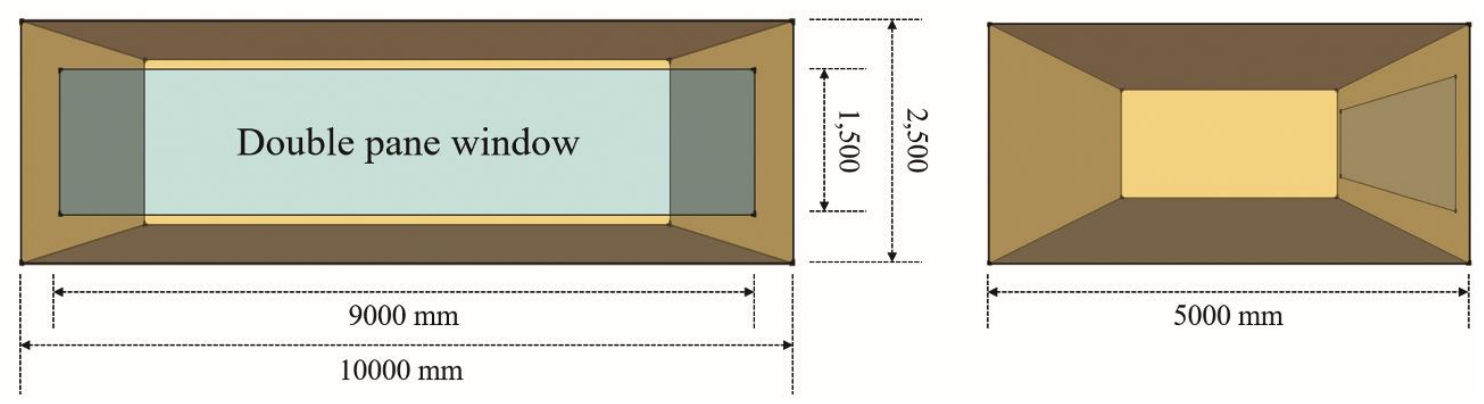

Fig. 2 The residential building molded by EnergyPlus program

\subsection{Building modeling and window application}

Fig. 2 and Table 4 show the building and basic information modeled in EnergyPlus to apply the previously modeled windows. The location of the building is assumed to be Seoul, and its purpose is residential. The building is also $10 \mathrm{~m}$ wide, $5 \mathrm{~m}$ deep, and $2.5 \mathrm{~m}$ high. The incense of the building is south, and a window of $9 \mathrm{~m}$ wide and $1.5 \mathrm{~m}$ high is installed on the south wall. In addition, the weather data applied for simulation was used for the standard weather data of Seoul, which is provided by a domestic accredited institution.[10] Table 5 also shows the structure and heat flow rate of each shell constituting the building. The building was modeled as a concrete structure, and the heat permeation rate of each envelope was constructed to meet the heat permeability standard of the central region suggested in the 'Energy-Saving Design Standard of Buildings'.[11]

Table 4 Overview of the standard building

\begin{tabular}{cccc}
\hline Site location & $:$ Seoul & $\begin{array}{c}\text { Length of } \\
\text { building }\end{array}$ & $: 10 \mathrm{~m}$ \\
\hline Latitude & $: 37.34$ & $\begin{array}{c}\text { Width of } \\
\text { building }\end{array}$ & $: 5 \mathrm{~m}$ \\
\hline Longitude & $: 126.57$ & $\begin{array}{c}\text { Height of } \\
\text { building }\end{array}$ & $: 5 \mathrm{~m}$ \\
\hline $\begin{array}{c}\text { Direction of } \\
\text { building }\end{array}$ & $:$ Corrected south & Window size & $: 9 \mathrm{~m} \times 1.5 \mathrm{~m}$ \\
\hline
\end{tabular}


Table 5 The structures of each building envelope

\begin{tabular}{|c|c|c|c|c|}
\hline Structure & Type of material & $\begin{array}{l}\text { Thickness } \\
(\mathrm{m})\end{array}$ & $\begin{array}{l}\text { Conductivity } \\
(\mathrm{W} / \mathrm{m} \cdot \mathrm{K})\end{array}$ & $\begin{array}{l}\text { Thermal transmittance } \\
(\mathrm{W} / \mathrm{m} 2 \cdot \mathrm{K})\end{array}$ \\
\hline \multirow{5}{*}{ Floor } & Concrete slab & 0.21 & 1.4 & \multirow{5}{*}{$\begin{array}{c}0.178 \text { (Domestic standard: } \\
0.180 \text { ) }\end{array}$} \\
\hline & Insulating material & 0.17 & 0.034 & \\
\hline & $\begin{array}{l}\text { Auto-cleaved Lightweight Concrete } \\
\text { (ALC) }\end{array}$ & 0.04 & 0.15 & \\
\hline & Mortar & 0.04 & 0.72 & \\
\hline & Finishing material & 0.005 & 0.16 & \\
\hline \multirow{3}{*}{ Wall } & Concrete wall & 0.18 & 1.4 & \multirow{3}{*}{$\begin{array}{c}0.258 \text { (Domestic standard: } \\
0.260)\end{array}$} \\
\hline & Insulating material & 0.12 & 0.034 & \\
\hline & Gypsum board & 0.01 & 0.17 & \\
\hline \multirow{5}{*}{ Roof } & Mortar & 0.08 & 0.72 & \multirow{5}{*}{$\begin{array}{c}0.142 \text { (Domestic standard: } \\
0.150 \text { ) }\end{array}$} \\
\hline & Concrete slab & 0.21 & 1.4 & \\
\hline & Insulating material & 0.09 & 0.035 & \\
\hline & Air cavity & 0.1 & 0.025 & \\
\hline & Gypsum board & 0.01 & 0.17 & \\
\hline
\end{tabular}

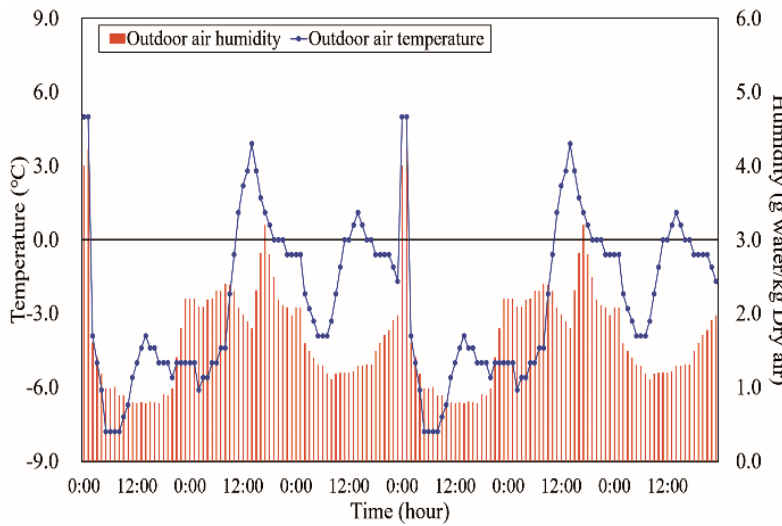

Fig. 3 Hourly outdoor temperature and humidity

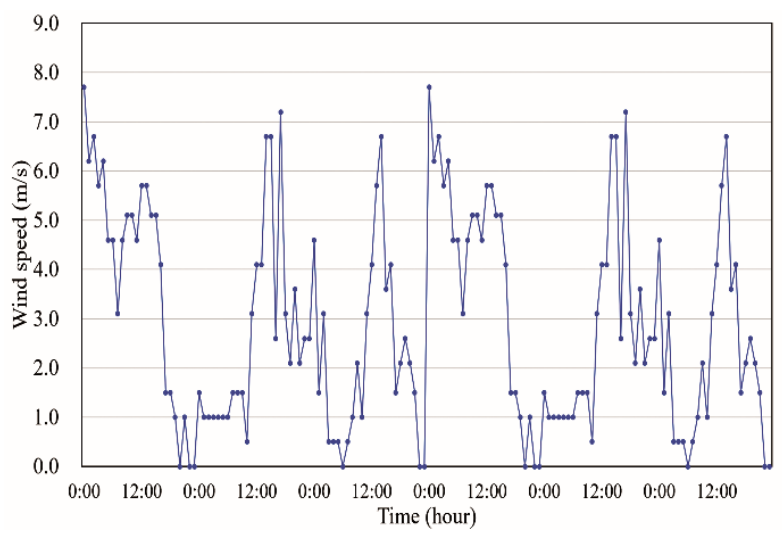

Fig. 5 Hourly wind speed

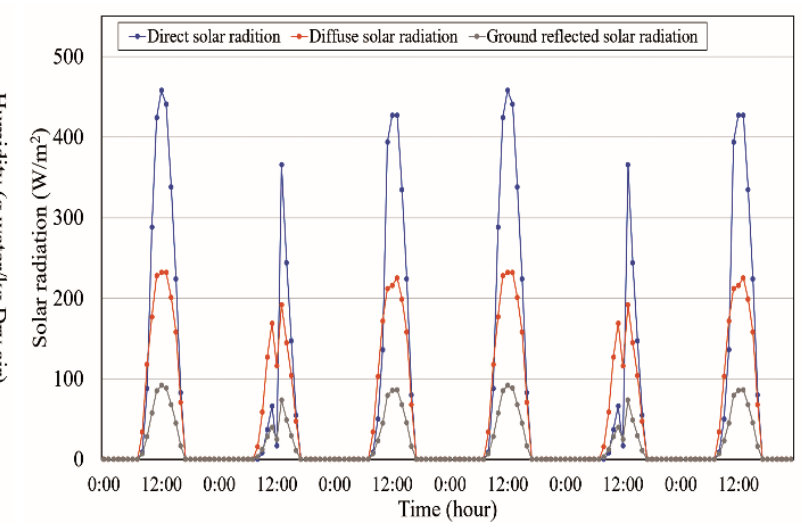

Fig. 4 Hourly direct, diffuse, and ground reflected solar radiations

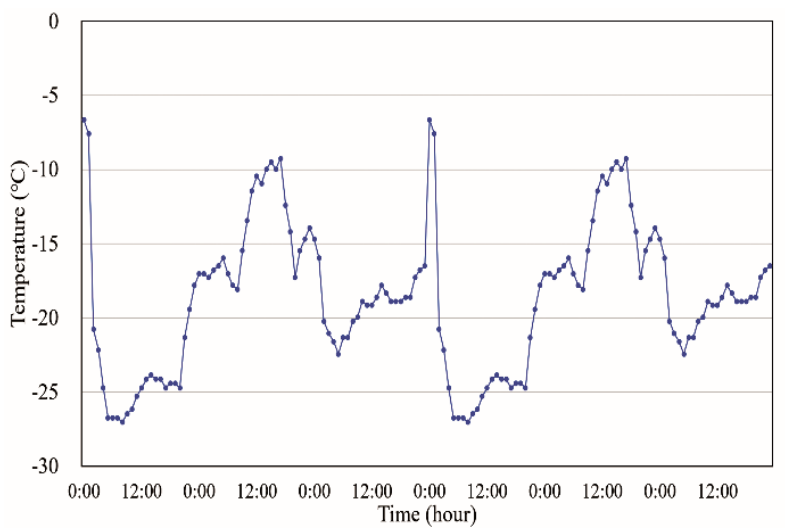

Fig. 6 Hourly sky temperature 


\subsection{Indoor and outdoor environmental conditions}

\subsubsection{Outdoor conditions}

Among the standard weather data applied to EnergyPlus, the analysis period was applied for about 1 week from 0:00 on January 1 to 0:00 on January 7. Each data of weather data was input by time, so the result of energy performance of double glass was also analyzed based on hourly data. Fig. 3, 4, 5, and 6 are representative data among hourly weather data for one week, and show outdoor temperature, solar radiation, wind speed, and puncture temperature.

\subsubsection{Applying Air conditioning equipment}

For indoor air conditioning and heating equipment, an electric air system including an electric heat exchanger was applied, and Table 6 shows the characteristics of the system. The indoor heating and cooling set temperatures are $22^{\circ} \mathrm{C}$ and $25^{\circ} \mathrm{C}$, respectively, and the heat source supply capacity is set to be automatically calculated as infinity. The sensible and latent heat exchange efficiency by the total heat exchanger was applied to the maximum value of 0.9 in the simulation, and the external air condition was set to be calculated through the standard weather data described above.

\subsubsection{Indoor heating element and temperature control}

Indoor heat loss and heat acquisition factors were applied to occupants, lighting, bedding, and ventilation, and the hourly schedule of each element is shown in Fig. 7, 8, 9. First of all, it was assumed that a total of 4 residents live. There are no occupants from 8:00 to 18:00, and other time is set to 4 persons. In addition, the lighting use is the same as the occupant schedule, and the size of the lighting was applied as a ratio from minimum 0 to maximum 1 .

In particular, 8:00 18:00 without occupants was set to 0 without lighting, and 6:00-8:00 and 18:00-22:00 were applied to the maximum lighting usage rate of 1. In addition, from 22:00 to 6:00 the next day, it was assumed to be bedtime, and the minimum lighting was set to 0.1 . In addition, indoor infiltration was assumed to be an energy-saving building and applied once per hour [12], and indoor ventilation was set at 0.5 times per hour, citing domestic standards.[13]

Table 6 Indoor heating and cooling system

\begin{tabular}{|c|c|c|}
\hline Type & All-air method & very unit \\
\hline \multirow{4}{*}{ Indoor set-point } & Heating set-point & $22^{\circ} \mathrm{C}$ \\
\hline & Heating limit & No limit \\
\hline & Cooling set-point & $25^{\circ} \mathrm{C}$ \\
\hline & Cooling limit & No limit \\
\hline \multirow{6}{*}{ Supply air } & Maximum heating temperature & $50^{\circ} \mathrm{C}$ \\
\hline & Maximum heating humidity & 0.0156 (kg/kg Dry Air) \\
\hline & Maximum cooling temperature & $10^{\circ} \mathrm{C}$ \\
\hline & Maximum cooling humidity & 0.0077 (kg/kg Dry Air) \\
\hline & Temperature control & Heating \& cooling set-point \\
\hline & Air flow rate control & Autosize \\
\hline \multirow{3}{*}{ Return air } & Heat recovery type & Enthalpy \\
\hline & Sensible heat recovery rate & 0.9 \\
\hline & Latent heat recovery rate & 0.9 \\
\hline \multirow{2}{*}{ Outdoor air } & Outdoor air condition & Weather data \\
\hline & Flow rate control & Autosize \\
\hline
\end{tabular}




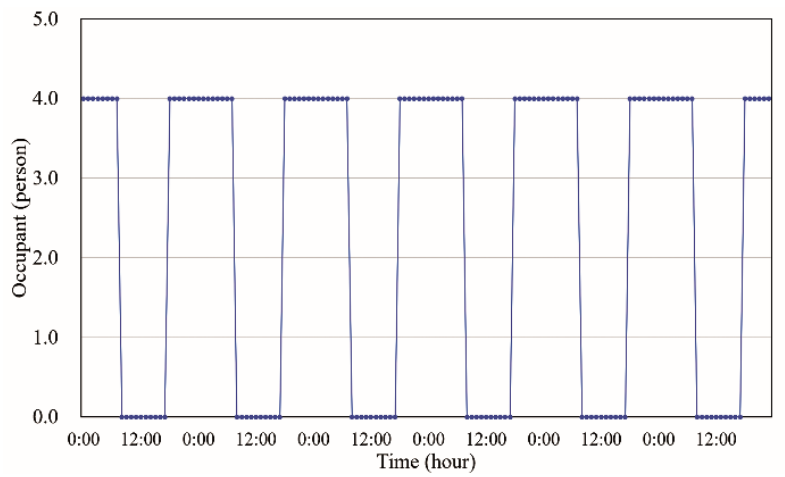

Fig. 7 Occupant schedule

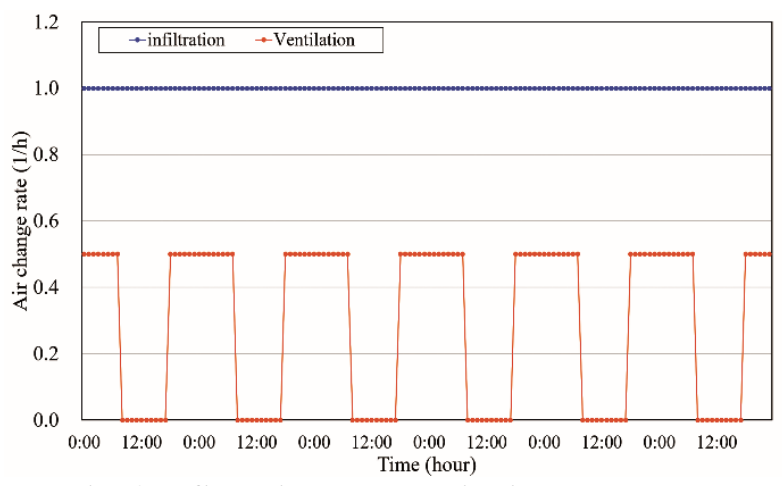

Fig. 9 Infiltration and ventilation schedules

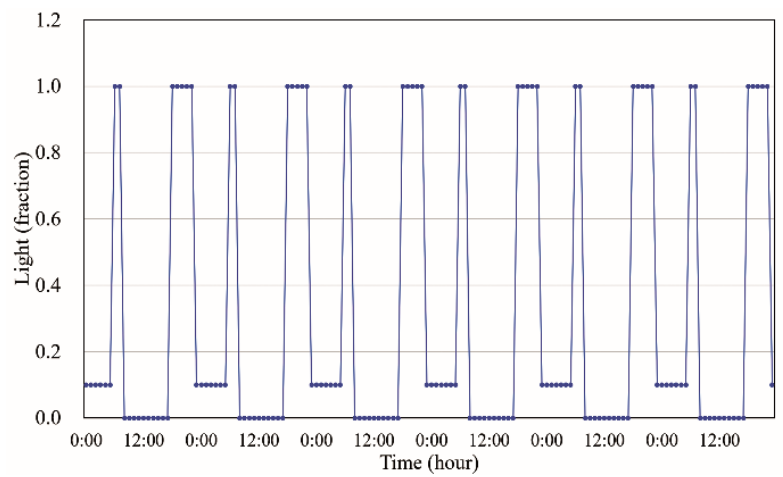

Fig. 8 Indoor light schedule

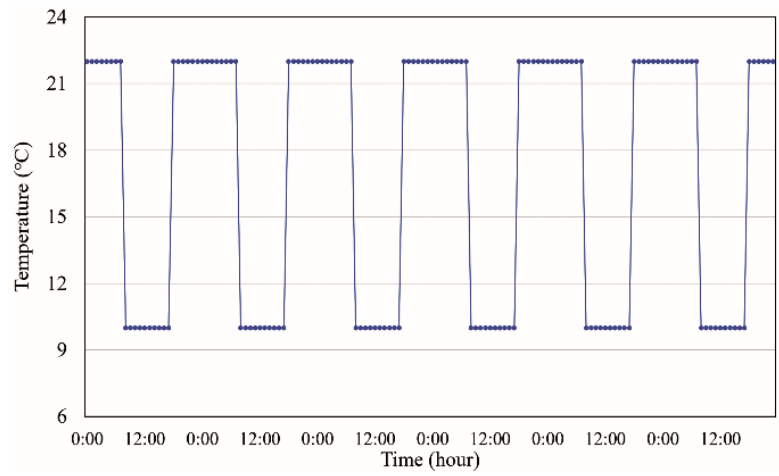

Fig. 10 Indoor temperature schedule

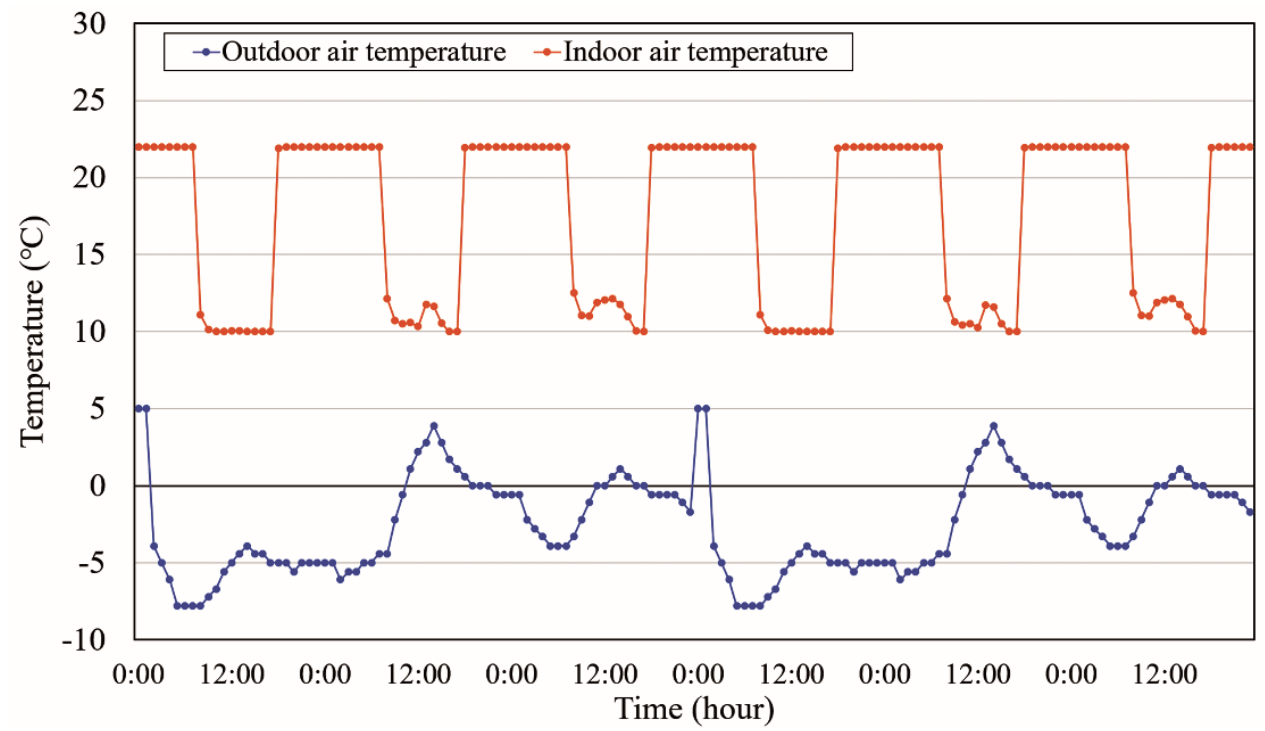

Fig. 11 Hourly indoor temperature changes

\section{Results and Discussion}

\subsection{Indoor temperature}

Fig. 11 shows the change in indoor temperature by hour from 00:00 on January 1 to 00:00 on January 7. As described above, the room temperature was set to maintain $22^{\circ} \mathrm{C}$. during the heating time and $10^{\circ} \mathrm{C}$. or higher in the non-heating time. Simulation results show that the indoor temperature maintains the set temperature from 18:00, the heating time, to $08: 00$, the next day, for all periods of one week, and $10^{\circ} \mathrm{C}$ or higher from $8: 00$ to 18:00, the non-heating time zone. It can be seen that it is controlled to maintain.

\subsection{Room surface temperature of double glass}

The flow of a certain amount of sensible and latent heat energy supplied to the indoor space through the heating system to the outside through the double glass is in the order of the indoor space, the indoor surface of the glass, the insulating gas, and the outdoor surface of the glass. Among them, minimizing the flow of heat energy between the interior space (Inside of Fig. 1), which is the initial flow, and the indoor side surface of the glass (Surface 4 of Fig. 1) reduces the total heat energy loss through the double glass. It is necessary to reduce the 
temperature difference between the two sides to the maximum by lowering the indoor temperature and increasing the surface temperature of the glass. However, in general, since the indoor heating set temperature is fixed at a constant time during the heating time, as a result, it can be said that maintaining the high indoor surface temperature of the glass can minimize heat energy loss. In addition, the indoor surface temperature of the glass changes according to the influence of the cold outdoor glass surface. At this time, the better the insulating performance of the injected gas, the higher the indoor surface temperature can be maintained. Therefore, prior to analyzing the energy performance of the double glass, when only the insulating gas was changed in the same glass, the first analysis was made on how the temperature distribution of the indoor surface of the glass varies with each gas. Fig. 12 shows the hourly data for the indoor surface temperature of the double glass injecting $\mathrm{CO} 2$ and Air, Ar, and $\mathrm{Kr}$ gases. After about 2 hours, after about 2 hours from 18:00 when heating started, the indoor surface temperature of the double glass was maintained at a stable state of about 10 to $14^{\circ} \mathrm{C}$. In the case of the distribution of the surface temperature according to the gas, the surface temperature of the indoor side of the double glass injected with air was the lowest, and the surface temperature of the $\mathrm{Kr}$ gas was the highest. On the other hand, it was confirmed that the surface temperature of the indoor side of the double glass in which $\mathrm{CO} 2$ and Ar gas was injected is located between the air and the $\mathrm{Kr}$ gas. Although the Ar gas was slightly higher than the $\mathrm{CO} 2$ gas, the surface temperature distribution of the two gases was analyzed to be almost similar. Therefore, it is expected to show this pattern in energy loss and heating energy consumption by double glass.

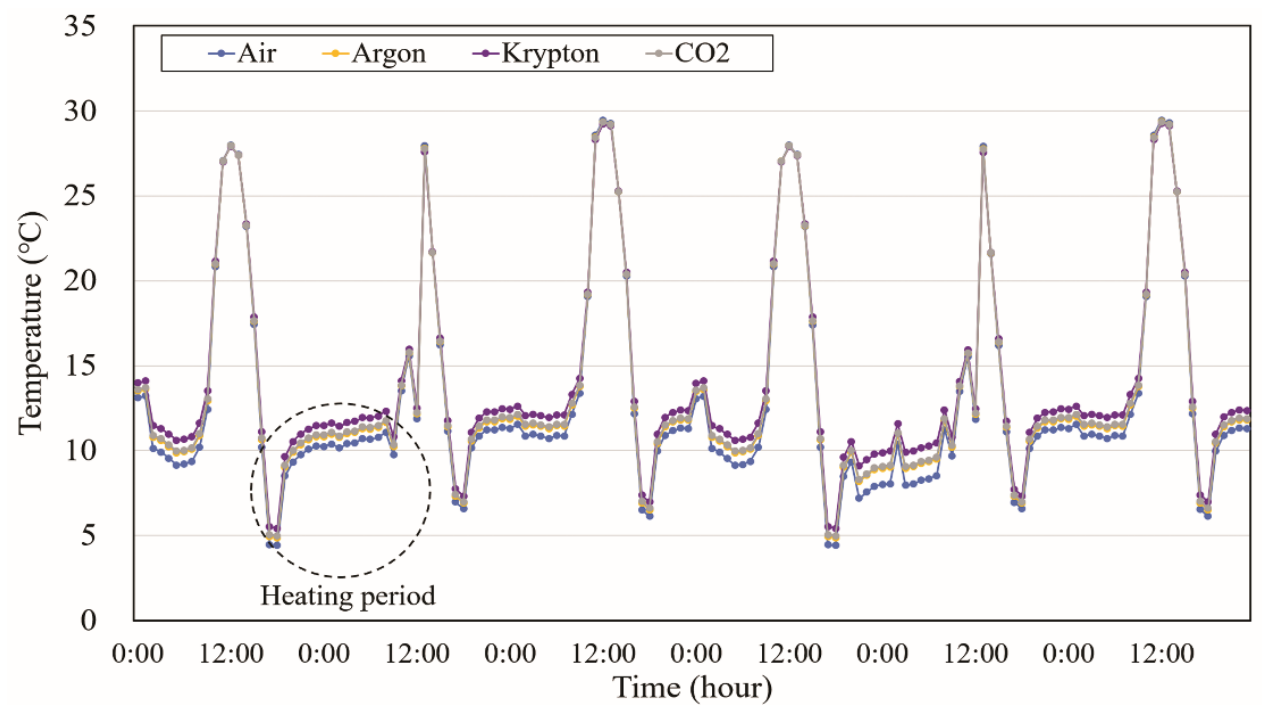

Fig. 12 Hourly temperature changes in indoor surface of the glazing

\subsection{Heating energy consumption}

Fig. 13 shows the amount of energy lost over time by the double glass injected with $\mathrm{CO} 2$ and Air, Ar, and $\mathrm{Kr}$ gas, and the amount of loss for all double glass was distributed in the range of about 0.3 to $0.9 \mathrm{kWh}$. In addition, the double glass injected with air showed the most thermal energy loss, while the double glass injected with $\mathrm{Kr}$ gas showed the least thermal energy loss. In particular, the double glass injecting CO2 and Ar gas appeared to have a medium level of Air and $\mathrm{Kr}$ gas, as shown in the pattern of the surface temperature described above, and it was analyzed that the heat energy loss by time of the two gases showed a similar pattern.

In addition, Fig. Fig. 14 shows the total heating energy consumption of a building with double gas injected with four gases during the entire simulation period. The double glass injected with air was $449.5 \mathrm{kWh}$, which was the highest in heating energy consumption, and the $\mathrm{Kr}$ gas injection was $441.2 \mathrm{kWh}$, which was the lowest consumption of heating energy. In comparison, the heating energy consumption of Ar gas and CO2 gas was $445.5 \mathrm{kWh}$ and $444.8 \mathrm{kWh}$, respectively, and Ar gas was slightly higher than CO2, but it was analyzed that it showed almost similar consumption.

When synthesizing the above analysis results, it was confirmed that the insulation and energy performance of the double glass injected with $\mathrm{CO} 2$ gas was almost the same as the U-value pattern suggested in the previous study. In particular, the $\mathrm{CO} 2$ double glass showed lower thermal insulation and energy performance than the $\mathrm{Kr}$ gas, but could exhibit higher performance than the traditional thermal insulation gas, Air, and showed almost similar performance to Arn gas. Therefore, it is judged that $\mathrm{CO} 2$ gas can be used as an insulating gas for double glass in buildings. Nevertheless, $\mathrm{CO} 2$ gas is one of the greenhouse gases. In consideration of this, when using this gas for double glass, it is considered that the gas injection and recovery technology should be secured together so that it is not exposed to the atmosphere during production and disposal. 


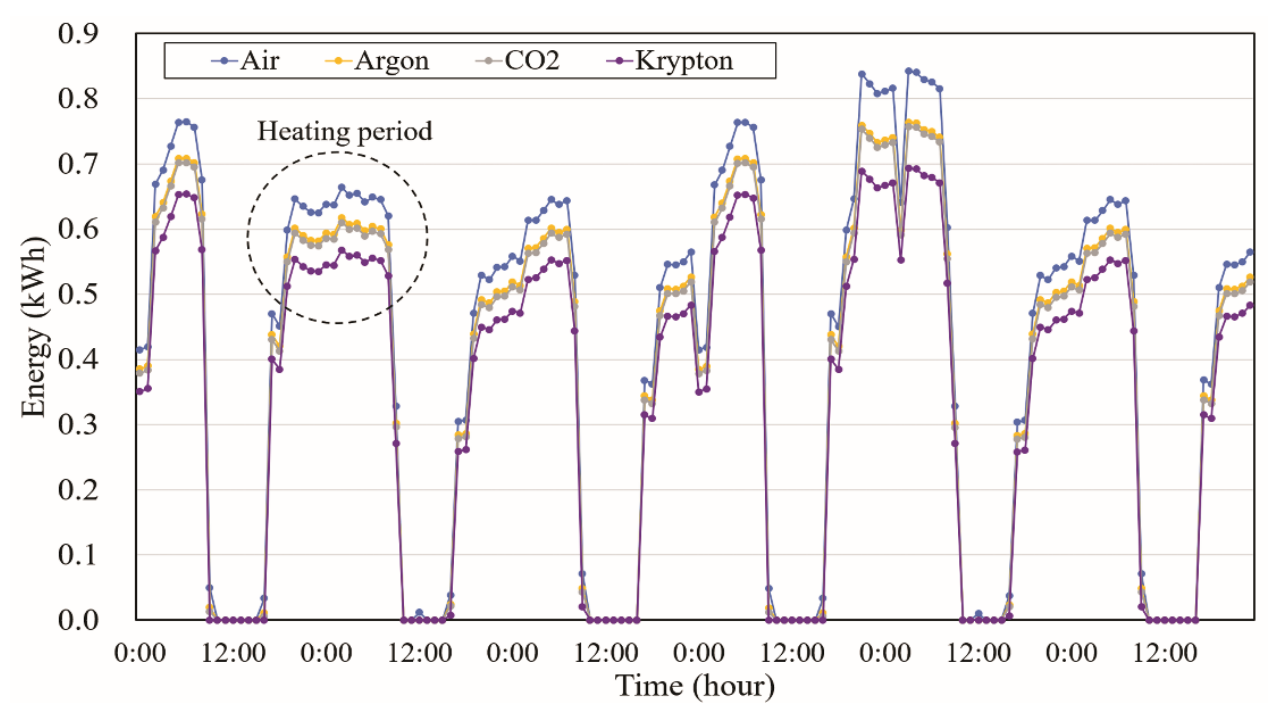

Fig. 13 Hourly heating energy lost by the glazing

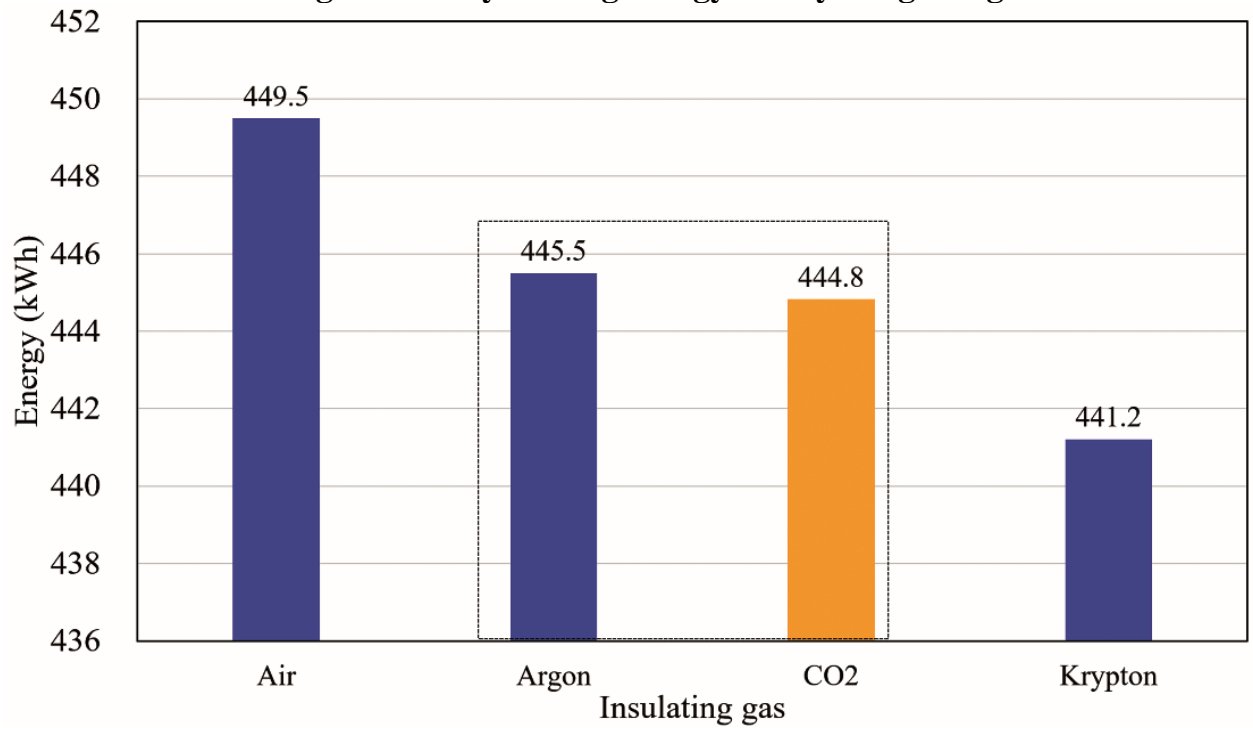

Fig. 14 Total heating energy consumptions

\section{Conclusion}

The study aims to analyze the thermal insulation and energy performance of the double glass infused with carbon dioxide (CO2), and the results obtained through this study can be summarized as follows.

(1) As a result of comparing the surface temperature of the indoor glass against the double glass of air, ar, and $\mathrm{kr}$ gas, which is the existing insulating gas, and the $\mathrm{CO} 2$ double glass proposed in this study during the heating period, the double glass with air injected was the lowest. It appeared, and the double glass in which $\mathrm{Kr}$ was injected was kept the highest. The double glass of $\mathrm{Ar}$ and $\mathrm{CO} 2$ gas maintained the surface temperature between the Air and $\mathrm{Kr}$ gases, and the surface temperature of $\mathrm{Ar}$ and $\mathrm{CO} 2$ appeared almost similar at the same time.

(2) As a result of comparing the amount of energy loss by hour by the double glass in which these gases were injected, as the result of the surface temperature, Air showed the most energy loss, whereas Kr gas showed the lowest energy loss. Looked. Also, the energy loss of $\mathrm{Ar}$ and $\mathrm{CO} 2$ gas was found to be between Air and $\mathrm{Kr}$ gas, and the energy loss was also analyzed to be almost the same.

(3) As a result of comparing the total heating energy consumption used in the building for about a week during the simulation period, $\mathrm{Kr}$ gas showed the lowest heating energy consumption, about $441.2 \mathrm{kWh}$, while Air showed the highest energy, $449.5 \mathrm{kWh}$. It was analyzed that it consumed. In comparison, for Ar and CO2 gas, it was found that the heating energy consumption was almost the same while maintaining the intermediate levels of Air and $\mathrm{Kr}$ gas, respectively, $445.5 \mathrm{kWh}$ and $444.8 \mathrm{kWh}$.

In the previous study and this study, the insulation and energy performance when $\mathrm{CO} 2$ gas, one of the greenhouse gases, was injected into the double glass was verified, and it was found that it exhibited similar performance to the existing Ar gas and thus was highly applicable as an insulating gas. Nevertheless, recent research trends focus on developing ultra-insulated glass with a zero-heat-permeability (U-value) of glass using a variety of materials and technologies. Therefore, future research will present the results of research on 
technology and performance verification to realize ultra adiabatic glazing using $\mathrm{CO} 2$ gas.

\section{Acknowledgment}

This work was supported by the National Research Foundation of Korea (NRF) grant funded by the Korea government (MSIP) (2018R1D1A1B07048848 2020R1I1A1A01066797).

\section{References}

1. Sim JG. Current status of CCU technology development, KEPCO Journal on electric power and energy, 2016 Vol. 2, No. 4, pp. 517-523.

2. Fang Y, Hyde T, Hewitt N, Eames PC, Norton B. Comparison of vacuum glazing thermal performance predicted using two- and three-dimensional models and their experimental validation. Solar Energy Mater. Solar Cells 2009, 93, 1492-1498

3. Fang $\mathrm{Y}$, Eames PC, Norton B, Hyde T, Huang $\mathrm{Y}$, Hewitt $\mathrm{N}$. The thermal performance of an electrochromic vacuum glazing with selected low-emittance coatings. Solar Energy 2010, 84, 516525.

4. Fang Y, Hyde TJ, Hewitt N. Predicted thermal performance of triple vacuum glazing. Solar Energy 2010, 84, 2132-2139.

5. Wullschleger L, Manz H, Ghazi Wakili K. Finite element analysis of temperature-induced deflection of vacuum glazing. Constr. Build. Mater. 2009, 23, 1378-1388

6. Baek SH, Analysis on Thermal performance of double-pane Unit filled carbon dioxide, Proceedings of the SAREK 2015 summer annual conference, 2015 Vol. 2015, No. 6, pp. 220-223.

7. EnergyPlus, Documentation engineering reference, 2016

8. Windows \& Daylighting, Glass Libary, Berkeley laboratory. https://windows.lbl.gov/tools/knowledgebase/articles/glass-library.

9. Windows \& Daylighting, Special gases library, Berkeley laboratory. https://windows.lbl.gov/tools/knowledge-base/articles/special-gases

10. The korean solar energy society, Korea standard weather data, 2009.

11. National law information center, Building energy conservation design standards, 2018.

12. Korean Institute of Architectural Sustainable Environment and Building System, 2013, Building airtightness criteria.

13. National law information center, Regulation for Facility in Building, 2017.

14. Priyadarshi, N., Bhoi, A. K., Sahana, S. K., Mallick, P. K., \& Chakrabarti, P. (2020). Performance Enhancement Using Novel Soft Computing AFLC Approach for PV Power System. In Cognitive Informatics and Soft Computing (pp. 439-447). Springer, Singapore.

15. Bhoi, A. K., Mallick, P. K., Liu, C. M., \& Balas, V. E. (Eds.). (2020). Bio-inspired Neurocomputing. Springer. 